\title{
Precision Livestock Farming in Animal Husbandry \& Dairy Science
}

\author{
Arda Aydin* \\ Department of Agricultural Machinery and Technologies Engineering, Faculty of Agriculture, Canakkale Onsekiz Mart University, Turkey.
}

*Corresponding author: Department of Agricultural Machinery and Technologies

Engineering, Faculty of Agriculture, Canakkale Onsekiz Mart University, Turkey.
Received Date: November 16, 2018

Published Date: November 21, 2018

\section{Importance of PLF in Modern Livestock}

Today, the world population has exceeded to seven billion. In the next 50 years, an increase of approximately three billion is expected. In addition to that income levels have dramatically risen in some countries like China, India and Brazil. According to global statistics, consumption of meat and other animal products is directly related to people's income levels [1]. For example, meat consumption increased as the income level of developing countries (China, India, Brazil, etc.) increased. As a result, the consumption of animal products, especially meat, has increased significantly. With this situation, food scenarios in the world are changing rapidly. Especially in order to meet the food needs of the world population, international cooperation, sustainable agricultural development, environmentalist approaches and the use of advanced technology in agricultural production should be focused on in a wider sense.

In particular, to meet the food requirement of growing world population, the requirement of more food production from small areas is come up. In recent years, the same changes in livestock production have also occurred. It has been adopted intensive farming and the number of animals per farmer reached a quite high number. Some decades ago, a farmer was busy with a few cattle, 1015 sheep's and poultry but these numbers have quite increased. In some countries it has possible to see farms with hundred thousand broilers or tens of thousands of dairy cows. According to the year 1967, pork meat increased by $294 \%$, bovine and buffalo meat by $180 \%$, egg by $353 \%$, chicken meat by $711 \%$ and sheep and goat meat by $202 \%$. More than 60 billion animals have been slaughtered only this year to meet people's food needs. In order to meet the demand for such dense meat and animal products, the producers have shifted to intensive livestock production in a shorter period and in a smaller area to grow more animals. This intensive farming has brought so many problems. The most important of these problems is that the farmer cannot control health and welfare of his animals because of the high number of animals per farmer. So, before while a farmer can spend his 10-15 minutes in a day for each animal, today he cannot spend his one minute for each animal. Today, the health and well-being of animals are ensured by experts and veterinarians visiting the farm and observing animals. However, this method does not provide sufficient contribution to animal husbandry which is very intensive today. In particular, the inability to detect diseases in time causes serious loss of life and property as well as high financial losses. In this regard, it is necessary to focus on issues such as the use of advanced technology in animal production. Farmers must be supported by technology and livestock production needs a different management model.

Because, another problem of livestock production is the environmental impact and needs to be a priority. For example, the livestock sector in France generates about 300 million tons of organic effluents and producing up to 1.8 million tons of nitrogen every year. However, increasing livestock production is directly linked with global food security and it depends on new technologies that can improve livestock production while minimising climate effects and protecting crops from the pests and diseases. Another point is that the relationship between animal and human health, around $70 \%$ of human pathogens and emerging diseases, are zoonotic and originated from animals. Therefore, the major points of interest in the next years will be continuous monitoring, management and controlling of animal health and welfare, regarding the environmental impact of the modern livestock farming. Fortunately, technology is getting cheaper continuously and consumes less energy to monitor different biological systems or process. Together with the increase in technology, it is becoming easier to understand biological systems by using their responses. The responses, reactions or change a process in animals can be measured by PLF approach using latest technological devices. These entire quantitative variables of animals are known as the bio-response. These responses can be caused by a change in its 
physiological or mental state or the environment. The health status of animals has been reflected by physiological status of them; for example, a lame cow starts lying down more frequently because of its leg problem. It is so important to quantify biological responses. Because, if we know how a system reacts, then we can anticipate or change what it will do. For example, the lameness of cows can be linked the measured activity [2].

Today, fully automated and continuous monitoring, controlling, technologically possible, and it is becoming more feasible to use this technology with Precision Livestock Farming (PLF) approach in the farms. PLF is a management system of livestock farming by automatic and continuous monitoring and controlling the health, welfare and production of animals. The general objective of PLF is to develop fully automated tools to continuously monitor animals' health, welfare and production with a non-invasive and nonintrusive way. The main purpose of these systems is not to replace eyes and the ears of the farmers but to support them, because it is very important to detect any kind of problem at an early stage to avoid a negative impact on the welfare or the production of animals. The novel technologic systems can complete the talent of inspectors, veterinarians and farmers.

PLF is a fully automated tool that can monitors animals continuously as $7 / 24$. It can also bring clear benefits in livestock production, including early detection, trend extraction, and processing of huge dynamic data [2]. Consequently, PLF techniques can allow to farmers and veterinarians to take immediate management actions in time [3]. Farmers can continuously and automatically monitor his animals, collect real time information and manage it to show people that livestock productions like meat and milk are safe for the consumption and environmentally sustainable. Therefore, this challenging approach of PLF should be transposed to practice. However, this is only possible when teams composed of different research fields, like physiology, zoology, and technology. In a word, to achieve this, "technology science" and "animal science" need to collaborate!

\section{Acknowledgment}

None.

\section{Conflict of Interest}

No Conflict of Interest.

\section{References}

1. FAO (2012) "Food and Agriculture Organization of the United Nations". In: World Livestock 2011.

2. Aydin A (2016) Automated Monitoring Systems to Assess Gait Score and Feed Intake of Broilers.

3. Aydin A (2017) Development of an early detection system for lameness of broilers using computer vision. Comput and Electron in Agric 136: 140-146. 